\title{
The Psychological Impact of Media on Adolescents
}

\author{
Ms. Agnes Monica Victor, \\ Lecturer, King Saud bin Abdulaziz University for health sciences, Riyadh, KSA.
}

\begin{abstract}
Adolescents throughout the country regularly use the internet, cell phones, and video games to gather information and communicate with each other. This ability to interact with others is the unique feature of social media which provides powerful new ways for adolescents to create and navigate their social environments. Adolescent's psychological impact of media occurs simultaneously with their developing identity, emerging sexuality, physical development, and moral consciousness (Chicago, John and Catherine, 2011). In recent years, electronic games, home computers, and the Internet have assumed an important place in our lives. This paper presents a review of the research on the impact of home computer use on the development of children and adolescents. Time use data are presented along with a discussion of factors such as age, gender, and ethnicity, which impact the time spent on computers as well as the activities engaged in. Research on the impact of computer use on cognitive skill and academic development, social development and relationships, and perceptions of reality and violent behavior is reviewed. The paper concludes with recommendations for future study in order to better understand the growing impact of computers on our youth (Purcell, 2011).
\end{abstract}

\section{Introduction}

The role of media in the adolescents has undergone a "revolutionary change". Recent research has shown that connections between children playing violent video games can cause later aggressive behavioral problems. In retrospect studies also shown a twelve percent increase in aggressive behavior after watching violent television as well. Some parents and psychologists have said that there are children who benefit from the proficiency and coordination of playing video games while others disagree. Critics of video games claim that watching violent television is less detrimental due to the children not physically playing out the violence (Child Development Institute, 2003). Research has also shown heavy viewers, which is four or more hours a day, put in less effort at school, have poorer reading skills, play less friendly with friends, have fewer hobbies and activities, and are more likely to be overweight. The American Psychological Association says there are three major effects of watching violence in the media (i.e. Video games/television) children may become less sensitive to the pain and suffering of others, children may be more fearful of the world around them, and children may be more likely to behave in aggressive or hurtful ways toward others (Clifford,2009).

\section{Social Media Usage Habits}

Chatting is the most common activity among users in the Arab world, followed by reading posts added by other people. Facebook and what's App are the most used social media channels across the Middle Eastern countries. While Face book was the top used social media channel on the aggregate level. On average, one third of users spend less than 30 minutes per session when using social media, and 5\% spend more than 4 hours per session. More than half the users are most active on social media during evening hours.More than half the users in the World use social media primarily to connect with people. While gaining information, watching videos, listening to music and sharing photos came as the second top main reason for using social media. (Arab Social Media Report, 2015)

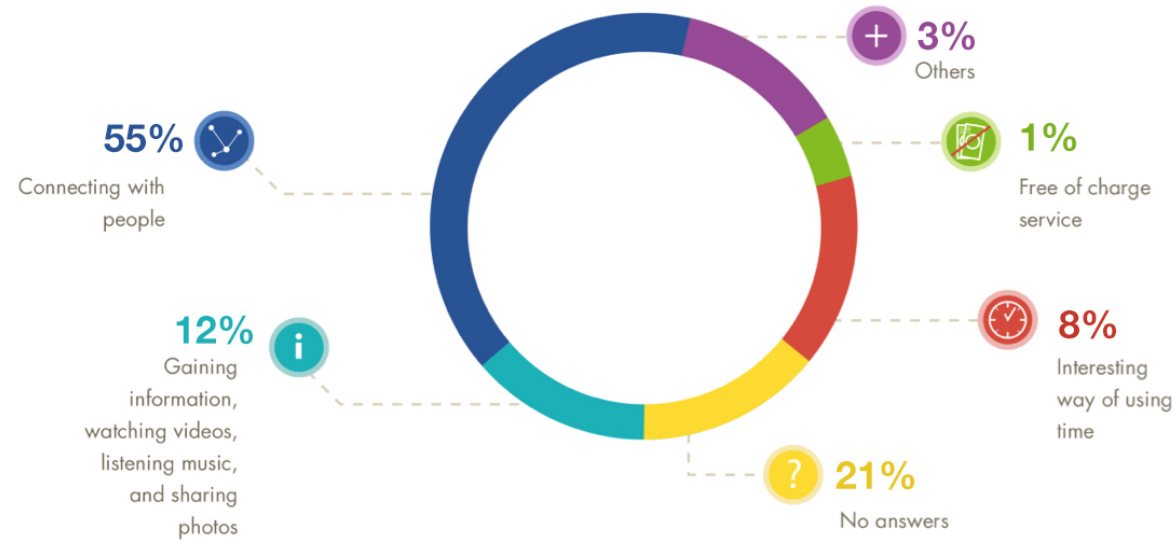




\section{Average Length Of Session When Using Social Media}

Populations in the Arab world are considered youthful since more than one-third of the population in each country consists of people aged 25 years or younger. Youth represents the majority of social media, as of June 2013 the percentage of total users between 16 and 34 years was 77\%. Also, in May 2014 the percentage of total Facebook users between 15 and 29 years old reached to $67 \%$.

\section{Most Commonly Used Social Media}

- Text Messaging- Cell phone feature $-75 \%$ of all teens own a cell phone and $88 \%$ of cell phone-owning adolescent users text $72 \%$ of all teens use text messaging

- Social Networking Sites- Facebook, Twitter, Linkedin, Messenger, Whats app - 73\% of young adults have used a social networking site

- Online video sites - YouTube.com- 63\% of online adolescents watch online videos

- Online gaming $-61 \%$ of online youth play games online, including multiplayer online games

- Blogging within social networking sites - Facebook $-52 \%$ of online teens have commented on a blog.

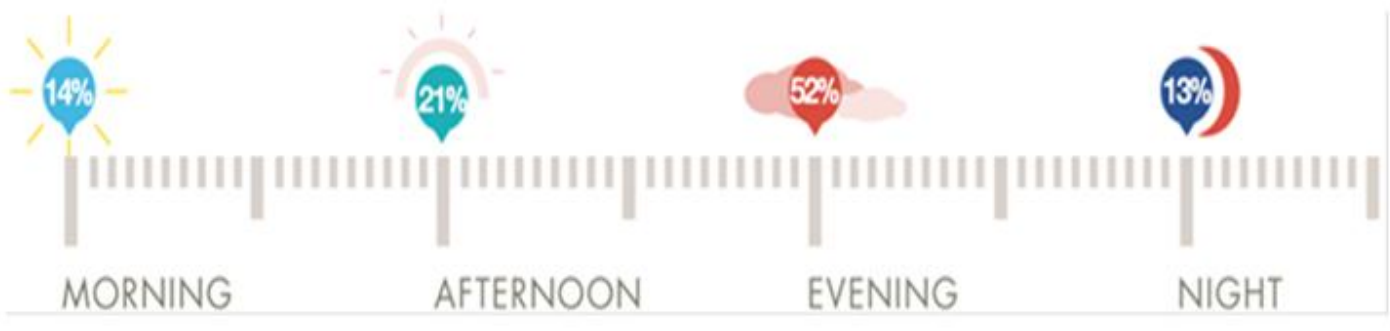

Source: (Lenhart.A, 2010) except for Online video sites (Nielsen, 2009) \& Online gaming (McAfee, 2010)

\section{Benefits Of Social Media On Adolescent Health}

Overall, social media use is associated with many benefits for adolescent health and development. Most of the adolescents use online networks to extend the friendships they already have from other areas of their life, such as school, religious organizations, sports and other local activities. Social networking sites provide a way for teens to experience connectedness and opportunities to learn from each other. Social media can provide a supportive environment to explore passion, friendship, and social status, while also providing an opportunity to share and discuss their taste in music, knowledge of television and movies, online videos/games, and other aspects of their culture (Ito, 2008).

\section{Socialization and Communication}

Social media sites allow adolescent population around the world to accomplish online tasks that are important to them offline: staying connected with friends and family, making new friends, sharing pictures, and exchanging ideas. Social media participation also can offer adolescents deeper benefits that extend into their view of self, community, and the world, including opportunities for community engagement through raising money for charity and volunteering for local events, including political and philanthropic events( Ito M, Horst $\mathrm{H}$, Bittani M,2008). Also, it helps in the enhancement of individual and collective creativity through development and sharing of artistic and musical endeavors and growth of ideas from the creation of blogs, podcasts, videos, and gaming sites. Expansion of one's online connections through shared interests to include others from more diverse backgrounds and fostering of one's individual identity and unique social skills (Boyd,2008).

Social networking sites can allow the adolescent population to find support online that they may lack in traditional relationships, those who are living with an illness or disability, or those who may feel physically unattractive or socially reticent (Blumenfeld and Cooper, 2010). They look to social networks as a key source of information and advice in a critical developmental period with $57 \%$ of social networkers saying they look to their online social network for advice (Nielsen, 2009). They also use online searches to gain answers to many of their health concerns with $31 \%$ of online users getting health, dieting, or physical fitness information from the internet. Seventeen percent of the population who use the internet report they use it to gather information about health topics that are hard to discuss with others, such as drug use and sexual health. Adolescents from lower income families are more likely to use online social networks (80\%) than from wealthier households $(70 \%)$ (Lenhart, 2010). They have found that they gained more independence and freedom through owning a cell phone that allows them to communicate with their parents and that they often use voice calling to seek out social support when needed to discuss personal matters (Lenhart, Ling, Campbell \& Purcell, 2010). 


\section{Enhanced Learning Opportunities}

Middle and high school students are using social media to connect with one another on homework and group projects (Boyd, 2008). For example, Facebook and similar social media programs allow students to gather outside of class to collaborate and exchange ideas about assignments. Some schools successfully use blogs as teaching tools, (Borja, 2005) which has the benefit of reinforcing skills in English, written expression, and creativity.

\section{Accessing Health Information}

Adolescents are finding that they can access online information about their health concerns easily and anonymously. Excellent health resources are increasingly available to youth on a variety of topics of interest to this population, such as sexually transmitted infections, stress reduction, and signs of depression. Adolescents with chronic illnesses can access Web sites through which they can develop supportive networks of people with similar conditions (Lenhart, Purcell, Smith, Zickur, 2010). The mobile technologies that they use daily, namely cell phones, instant messaging, and text messaging, have already produced multiple improvements in their health care, such as increased medication adherence, better disease understanding, and fewer missed appointments (Krishna, Boren, Balas, 2009). It is also proved that the new social media venues have mobile applications, teenagers will have enhanced opportunities to learn about their health issues and communicate with their doctors. However, because of their young age, adolescents can encounter inaccuracies during these searches and require parental involvement to be sure they are using reliable online resources, interpreting the information correctly, and not becoming overwhelmed by the information they are reading. Encouraging parents to ask about their children's and adolescents' online searches can help facilitate not only discovery of this information but discussion on these topics.

\section{Adolescent Mental Health And Social Media}

Most adolescents surveyed who are regular media users have lots of friends, get along well with their parents, and are happy at school (Rideout, 2010). However, peer rejection and a lack of close friends are among the strongest predictors of depression and negative self-views (Hartup, 1996). Young adults who are the heaviest media users report being less content and are more likely to report that they get into trouble a lot, are often sad or unhappy, and are often bored (Rideout, 2010). In California, 21\% of them surveyed were found to be at risk for depression (California Health Interview Survey, 2005). In addition, 68\% of girls nationally report having a negative experience on a social networking site. Some of them have reported that Facebook can incite fights, especially with the creation of "burn" pages created for the explicit purpose of taunting or teasing others (Boyar, 2011).Female and male adolescent tend to compare themselves with models in television advertisements more frequently at this age and as a result both the gender feel in secured and lack of confidence in themselves. This also led to unhealthy lifestyle which is one of the most serious things to be taken care of now a days. Girls with stick to crash diet to get unattainable body of those models in advertisement and boys often resort to the use of steroids and over exercising to achieve a perceived muscular body ( Droomgoole,2006).Use of social media also creates an opportunity for emotional distress from receiving threatening, harassing, or humiliating communication from another teen, called cyberbullying. In California, approximately $23 \%$ of them report being threatened by a peer. Cyberbullying appears similar in prevalence to offline bullying (Lenhart, 2007). Cyberbullying has been shown to cause higher levels of depression and anxiety for victims than traditional bullying and has also been connected to cases of youth suicide known to engage in reading hurtful comments days before their suicide attempts (Kowalski, 2010).

Dr. Sonakshi Singh in a case study told that adolescents are exposed to an approximate of 9-15 hours of television/internet per week, internet being the strongest of all media tools. She stated that due to the increase in the awareness in the Indian society about the worth of women children too particularly boys are now learning that girls can do whatever the boys can. This is in a way is reducing the vast gender gap that exists in gender roles in the society that have existed for so long. She also points out that the adolescents experience physical and mental maturity much earlier. The 19 year olds are no longer referred to as teenagers a more suitable term for this age group is young adults. Having mentioned that she states that it is important for the parents to limit the use of internet.The excessive usage of laptops and tablets will create an increasingly detrimental effect upon the health in several psycho-socioeconomic ways leading to issues such as obesity, depression and low motivation. She also stated that the way in which men and women react to similar advertisements in a very different manner. While women are influenced by emotional and positive content, men are influenced by adventure and competition. (Barve G, Sood A, Nithya S, Virmani T (2015).

\section{Texting/Sexting}

While most young adults use messaging responsibly, it is still an extremely powerful and private communication tool that can be used irresponsibly. With texting, teens cannot see the reaction of the person receiving the message, so their actions can be separated from the consequences (Commonsense media, Parenting Tip Sheet, 2010). 


\section{Violent Media}

Everything that young adults see or hear in the media early on in their lives affects them in some way. Positive parenting role models indicate that in the best interest of our children we should limit their exposure to violent acts. Unfortunately, violence is one of the most popular forms of entertainment. Over sixty percent of television shows being shown in prime time contain some form of violence. There are two very opposite sides of this issue. The media who market the violent television, video games and other forms of entertainment argue this is safe entertainment and the others argue that violence promotes violence. Current research tends to agree with the proponents who argue that violent media is associated with aggressive behavior. Risky behavior by children and young adults can include violence against others, lack of remorse for consequences. The type of faulty thinking creates stressors in children which can lead to the onset of many different symptoms. Children who view media violence are more likely to have increased feelings of hostility, decreased emotional response to the portrayal of violence and injury that lead to violent behavior through imitation. For example, the act of imitating what they have seen on a television show causes injury to themselves or others around them.

Another view from researchers suggests that performing violent acts in video games may be more contributing to children's aggression than passively watching violent acts on television. According to this view, the more children practice violent acts, the more likely they are to perform violent acts (Cesarone, 1994). In most video games women are usually portrayed as persons who are acted upon rather than as initiators of action, in the extreme they are depicted as victims. The movie the Matrix for example was said to be the triggering factor to the violent high school students that wore trench coats. They were eventually arrested for trying to play out their role as "The One." Another research has found that males play video games more often than women which may be the producing factor of such violence in video games. It is believed that acting out such violence as opposed to just viewing the violence causes the children to become more familiar with how to act out violence without consequences. On the other hand the makers of these violent types of media such as movies, video games and television argue that violent children are drawn towards these types of violent entertainment. These people believe that the child must have been exposed to more than just programming in order to exhibit behaviors that they may have seen on television or in the media. Some will argue though that the real effect is so small that in fact one hypothesis suggests that exposure to violent media can actually provide a healthy release for the frightening emotions of children and young adults. At the age children begin to play video games they have not quite developed the ability to distinguish between what is reality and what it's not. This can cause young children to act upon the violence they have viewed on television, video games and such, not knowing that what they are doing is wrong or inappropriate.

The only part of the issue that researchers do agree about is that violent media types are not the only cause of children committing violent acts. The involvement of parents in what their children watch, how the family interacts with each other, what the children are exposed to in their environment are also indicators of how they will behave and what value system they will follow. In 1995 one research revealed that both impulsive and reflective young adults showed increased amounts of violent aggression towards play objects after playing violent and non-violent video games. However, in a contradictory study it was found that there was not a difference between children that were exposed to violent media and those who were exposed to nonviolent media. The catharsis theory disputes the claim that violent video game content encourages aggression. This theory suggests that the emotional drive evoked by violent video game play reduces the chance of a child actually exhibiting violent behavior; the child's fantasy play and imagined actions causes the child to have reduced urges to act out aggression in actual behavior (Ivory, 2001).

Negative effects of advertisements include several developmental both psychological and physiological. Media and commercials general a lack of moral ground creating a wide expanse of grey which helps teenagers justify wrong actions. It creates gender stereotypes and incites aggression. Effects of media also include the lack of patience and social apathy. All these factors are directly responsible for the depression and low social image which is a grave issue and is being faced by most teenagers. The physiological effects of media are the lack of concentration, obesity and sluggishness. The teenagers also face insomnia due to not having enough physical stimulation. The time spent on screen leads to mental fatigue but not physical which today is the root cause of insomnia. The positive effects of media according to the professionals range from creating awareness about the different gender roles, and norms of the society. For e.g. the adolescents are more aware of the need to vote, or wear seatbelts and not drink and drive. They realize the negative effects of smoking and drinking much more through these adverts. Furthermore the ads like "why should boys have all the fun" create a sense of equality which otherwise is missing in the Indian society. While some psychologist believe that boys are more open with the problems they experience the others believe that girls are more vocal. However the subjects of these issues faced are largely similar leading from issues with peers, disruptive family environment and failure in achieving (Barve G, Sood A, Nithya S, Virmani T (2015). 


\section{Influence Of Advertisements In The Media}

Many social media sites display multiple advertisements such as banner ads, behavior ads (ads that target people on the basis of their Web-browsing behavior), and demographic-based ads (ads that target people on the basis of a specific factor such as age, gender, education, marital status, etc) that influence not only the buying tendencies of preadolescents and adolescents but also their views of what is normal. It is particularly important for parents to be aware of the behavioral ads, because they are common on social media sites and operate by gathering information on the person using a site and then targeting that person's profile to influence purchasing decisions. Such powerful influences start as soon as children begin to go online and post.

Privacy

Most studies show that adolescents do care about privacy. When they are concerned about risks, they will engage in privacy protecting behaviors, such as adjusting their profiles to "private" from "public" access, refusing to provide identifying information or false information, and avoiding certain websites (Youn, 2009). However, most youth do not read websites' privacy policies or may be unaware that their information is at risk of disclosure to third parties like advertisers. Though concerned about talking to people they don't know online, they appear to be less worried about posting information about themselves. Twenty-one percent of young adults say it is safe to post personal information, including photos, online to a public profile (Cox, 2007).

\section{For Parents and Caregivers:}

\section{Recommendations}

Awareness Parents and caregivers need to educate themselves about social media and the ways they use, as well as the common risks, to help them understand and navigate the technologies.

Engagement Family discussions are positive for adolescents and can result in less risky online behaviors more of those who said their parents have talked to them "a lot" reported (Cox, 2007).

Respect for privacy and empowerment For parents and caregivers, discussing media content with their children can be an effective strategy to reduce the amount of personal information disclosed more so than prohibiting access, as they often perceive monitoring as a violation of their privacy (Ito, 2008).

\section{For Community:}

Greater resources need to be allocated to schools, libraries and community organizations to assist them in adopting risk management strategies and to provide education about online safety issues.

Resources are needed for social services and mental health professionals who work with minors and their families to extend their expertise to online spaces and work with other members of the community to identify atrisk youth and intervene before risky behavior results in negative outcomes (Berkman, 2008).

Technological solutions Internet providers such as Google and Yahoo, and social networking sites, such as Facebook and YouTube, need to continue to work with parents and policy makers to create awareness and opportunities for privacy protection of youth and to develop technologies that can assist teens in staying safe.

-Health providers Medical and mental health providers need to include routine screenings to assess risk for depression that consider a teen's social media use. For example, assessing the amount of time spent using media including online activities or inquiring about online contacts with close friends vs. strangers, their willingness to meet someone offline, incidence of being harassed, harassing others.

Schools need to update media literacy guidelines to include explicit information on successful participation with new media forms, online risks, and education about consequences of their media use, including laws that pertain to them.

Research Evaluation research is needed on the success of social media-based interventions, particularly those focusing on urban and rural teens from low income families and those with poor home environments.

\section{Conclusion}

In conclusion, not one research conducted could prove either positive or negative long term outcomes of violent media. The fact of the matter is that parents should monitor and be more attentive to their children. In the act of a busy life we all tend to forget the real life issues. Parents need to pay more attention to their children's lives and not sit them in front of the television, weather it is for movies, video games, or general television shows. In my opinion this day and age most parents get too wrapped up in their own lives to be overly concerned about what their children are doing. Raising a child is hard enough in these days and all the outside media violence and it makes it ten times harder to steer your child in the right direction. All we can do as parents is pay attention to our children and stay involved in their lives before it is too late.

\section{References}

[1]. Arab Social Media Report,2015 Barve G, Sood A, Nithya S, Virmani T (2015) Effects of Advertising on Youth (Age Group of 1319 Years Age). J Mass Communicat Journalism 5: 260. doi:10.4172/2165-7912.1000260

[2]. Berkman Center for Internet and Society, Harvard Law School, Internet Safety Technical Task Force. (2008). Enhancing Safety and Online Technologies: Final Report of the Internet Safety Task Force to the Multi-State Working Group on Social Networking for the State Attorneys General of the United States. 
[3]. Blumenfeld, W.J. and Cooper, R.M. (2010). LGBT and Allied Youth Responses to Cyberbullying: Policy Implications. The International Journal of Critical Pedagogy, 3(1), 114-133. Retrieved on June 3, 2011 from http://freireproject. org/images/2321/JJCPv3_7.pdf

[4]. Boyar, R., Levine, D., \& Zensius, N. (2011). Tech SexUSA: Youth Sexuality and Reproductive Health in the Digital Age. Retrieved on May 30, 2011 from ISIS website: http://www.isis-inc.org/ISISpaper_techsx_usa.pdf

[5]. Boyd D (2008). Taken Out of Context: American Teen Sociality in Networked PublicsBerkeley, CA: University of California; 2008. Available at: www.danah.org/papers/TakenOutOfContext.pdf. Accessed July 16, 2010

[6]. Borja RR (2005). "Blogs" catching on as tool for instruction: teachers use interactive Web pages to hone writing skills. Educ Week. December14, 2005. Available at: www.iapsych.com/edblogs.pdf. Accessed July 16, 2010

[7]. California Health Interview Survey (CHIS). (2005). Retrieved on May 30, 2011 from website: http://www.chis.ucla.edu

[8]. Cesarone, Bernard, 1994, Video Games and Children ERIC Digest. http://www.kidsource.com/kidsource/content2/ video.games. html. Accessed October 26, 2003

[9]. Child Development Institute, 2003, Video Games and Children, http://www.childdevelopmentinfo. com/healthsafety/ videogamesandchildrens.html Accessed October 26, 2003

[10]. Chicago, IL: John D. and Catherine T (2011). MacArthur Foundation Reports on Digital Media and Learning. Retrieved on May 30 , 2011 from MacArthur Foundation website: http://www.macfound.org/atf/cf/\%7BB0386CE3-8B29-4162-8098E466FB856794\%7D/DML_ETHNOG_WHITEPAPER.PDF

[11]. Clifford, S. (2009, February 7). Straight talk on digital harassment for teenagers. The New York Times. Retrieved on May 30, 2011 from http://www.nytimes.com/2009/01/27/technology/27iht-adco.1.19705877.html

[12]. Cox Communications. (2007). Cox Communications Teen Internet Safety Survey, Wave II - in Partnership with the National Center for Missing \& Exploited Children ${ }^{\circledR}$ (NCMEC) and John Walsh (Fielded Among Young People Aged 13-17). Retrieved from http://www.cox.com/takeCharge/includes/docs/survey_results_2007.ppt\#271,1,Slide 1

[13]. Commonsense Media. (2010). Parent tip sheet: Commonsense on Text Messaging. Retrieved on May 30, 2011 from http://www.commonsensemedia.org/advice-for-parents/responsible- text-messaging-tips

[14]. Dromgoole A (2006) Media Effects and Body Image Perceptions on Youth.Youth Development Initiative.

[15]. Hartup, W.W. (1996). The company they keep: Friendships and their developmental significance. Child Development, 67, 1-13.

[16]. Ito M., Horst, H., Bittani, M., boyd, d., Herr-Stephenson, B., Lange, P.G.,Tripp, L. (2008) Living and Learning With New Media: Summary of Findings From the Digital Youth Project.

[17]. Ito M, Horst H, Bittani M, et al (2008). Living and Learning with New Media: Summary of Findings from the Digital Youth Project. Chicago, IL: John D. and Catherine T. MacArthur Foundation Reports on Digital Media and Learning; 2008. Available at: http://digitalyouth.ischool.berkeley.edu/files/report/digitalyouth-TwoPageSummary.pdf. Accessed July 16, 2010

[18]. Ivory, James D., 2001, Video Games and the Elusive Search for their Effects on Children: An assessment of Twenty Years of Research, http://www.unc.edu/ jivory/video.html. Accessed November 16, 2003

[19]. Kowalski, R.N. (2010). Alexis Pilkington Facebook Horror: Cyber bullies harass even after suicide. Retrieved on June 3, 2011 from website: http://www.huffingtonpost.com/2010/03/24/alexis-pilkington-faceboo_n_512482.html

[20]. Krishna S, Boren SA, Balas EA. Healthcare via cell phones: a systematic review. Telemed E Health. 2009;15(3):231-24

[21]. Lenhart A. (2007). Cyberbullying. Retrieved on June 3, 2011 from Pew Internet and American Life Project website; http://www.pewinternet.org/Reports/2007/Cyberbullying.aspx.

[22]. Lenhart A, Purcell K, Smith A., \& Zickuhr K. (2010). Social media \& mobile internet use among teens and young adults. Retrieved May 30, 2011 from Pew Internet \& American Life Project website: http://www.pewinternet.org/Reports/2010/Social-Media-andYoung-Adults.aspx

[23]. Lenhart A, Purcell K, Smith A, Zickur K (2010). Social Media and Young Adults. Washington, DC: Pew Research Center; 2010.Available at: http://pewinternet.org/Reports/2010/Social-Media-and-Young-Adults.aspx. Accessed July 16, 2010

[24]. McAfee, Inc. (2010). The secret life of online teens. Retrieved on May 30, 2011 from website: http://us.mcafee.com/enus/local/docs/lives_of_teens.pdf

[25]. Nielsen Company. (2009). How Teens Use Media: A Nielsen report on the myths and realities of teen media trends. Retrieved on May 30, 2011 from website: http://www.nielsen.com/content/corporate/us/en/search.html?q=How+Teens+Use+Media

[26]. Purcell, K. (2011). Trends in Teen Communication and Social Media Use. Retrieved May 30, 2011 from Pew Internet \& American Life Project website: http://www.pewinternet.org/Presentations/2011/Feb/PIP-Girl-Scout-Webinar.aspx

[27]. Rideout, V.J., Foehr, U.G., \& Roberts, D.F. (2010). Generation M2: Media in the lives of 8-18 year olds. Retrieved on May 15, 2011 from Kaiser Family Foundation website: http://www.kff.org/entmedia/upload/8010.pdf

[28]. Youn, S. (2009). Determinants of Online Privacy Concern and Its Influence on Privacy Protection Behaviors among Young Adolescents. The Journal of Consumer Affairs, 43(3), 389418. 